\title{
USE OF APPLICATIONS WITH GEOREFERENCED CONTACTS 'DATING APPS' TO IDENTIFY CREATIVE AREAS
}

\author{
PABLO TOMÁS CASTELLÓ, JESÚS LÓPEZ BAEZA* \& CARLOS PASTOR GARCIA \\ University of Alicante, Spain
}

\begin{abstract}
During the recent years, the use of social media has become a popular way of establishing and maintaining social interaction and relationships. For those networks based on geolocation (LBSN), their link to the urban environment and physical space offer great possibilities in regard to the observation, research and description of such. This paper uses public data from Wapo, a location-based social network utilized by male homosexual users. A new methodology will be proposed, which aims to update Gates' gay index by focusing on the density of users and the profile pictures. These app usage data will be cross-referenced with objective static data indicators related to demography, and socioeconomic data to observe correspondences. Thus, this paper utilizes indicators extracted from Wapo as an alternative and complementary methodology to observe the distribution of creative areas under certain conditions. It is established a theoretical link between inequality and the feeling of comfort regarding the perception of tolerance. This relation is experimented through the content observation of profile pictures within the app and the quantitative proportion of explicit displays of identity. It is observed that density of users remains independent from any socio-economic indicator. However, mathematical discordances found in the tendencies about the number of active users and the proportion of explicit profile pictures finds correspondence with areas known as creative and gay-friendly and potential gentrification.
\end{abstract}

Keywords: LBSN, social media, dating apps, creative areas.

\section{INTRODUCTION}

Dating apps based on geolocation have experimented an exponential growth over the recent years - Grindr reported over 2 million active daily users in 192 countries since its launch in 2009 [1]. Regarding the spatial component, this kind of social media has contributed to the generation of virtual public space where affective relations are established and maintained, leaving the physical spatial realm in the background of casual social interaction [2]. Those apps targeted to male homosexual users are currently modifying behavioral patterns in those spaces formerly known as the cartography of desire in the city - (such as saunas, queer bars, cruising sites, etc [3]). These apps allow collective and public spaces such as airports, offices and gyms to become new hook-upping spaces [4]. Thus, the progressive popularization of these tendencies contributes to the increase of production of new spatial codes [5] as new ways of interacting with and within public and collective spaces and eventually, redefine them.

In regard to the social component, gay dating apps allow the establishment of relations taking out the need of mobility to visit LGBT-defined spaces [6]. Beyond the seek of immediate sex [7], the diversity of users and social demands increased with the restriction of sexual content in profiles using machine learning and computational identification of content [8]. Thus aside from hooking-up, these apps have been used for queer activism in areas with a harsh perception of homosexuality (such as eastern countries and rural areas)

\footnotetext{
* ORCID: http://orcid.org/0000-0002-4092-1782
} 
allowing users to take a series of actions to promote a sense of identity and belonging to a community [9].

Even though the virtual realm has an imperative significance in the use of these apps, the link to the physical space is inevitable. Users are conditioned to the place where they are online through their GPS trace and thus they merge with the narrative of the place itself too [10]. Geotagged dating apps offer socio-behavioral information of certain places, which can be extracted and studied in order to gain knowledge of spaces [11] and eventually intervene them through policies related to social inclusion, social cohesion, or visibility of minorities or groups of exclusion.

\subsection{Dating apps in social studies}

Several studies [12], [13] have aimed to relate the presence of homosexual population to several other indicators. Florida [13] defines a creative class, which was born at the early 21 st century in occidental countries. This creative class is composed by a dense group of professionals, for which creativity is the main resource for their activities (architects, designers, artists, etc.) and are bounded to produce major changes in the way of working, living, aspiring, and several other fields of the everyday lifestyle where tolerance and openmindedness is involved [13]. Florida claims that the creative class is the engine for economic growth and that human creativity is the definite resource. Thus, he aims to measure it through several indicators (diversity index, bohemian index, among others) among which the gay index was included.

Whilst it is true that several scholars [14], [15] defend that higher-level educational areas are those that match a higher economic development being the presence of homosexual population just a circumstance, they admit a quantitative correspondence. Hence in this regard Florida [13] defines his gay index as "the density of homosexual people in a given case-study area".

In this paper, we implement the gay index to the user database of Wapo for all the neighborhoods of the city of Barcelona, Spain. Here we observe the density of users in correspondence to average income, and population and population density (Table 3 ).

In great urban areas such as Los Angeles or Paris, social inequality implies residential inequality in a dual city conceptualized model [16]. However, income distribution in Barcelona does not imply spatial segregation [17]. Sarasa's studies conclude that Barcelona is unequal but is not spatially segregated. However, one can notice different behavioral and residential patterns between classes [17, p. 39].

\subsection{Self-visibility through profile pictures}

Visual relations are a crucial element when studying spatial perceptions. Colomina [18], [19] refers to these visual trajectories as the base ground for dominance in architectural interiors, being the observer who exerts control over the observed. This relation takes materiality in several architectural typologies [20], [21] designed to exert dominance through vigilance. From a broader-scale perspective, the ability to watch is associated to the feeling of comfort when one sees and is seen by others [22]. When referring to interpersonal relations, one assimilates information from the visual field (or social field of vision) [23] and is aware of being observed and thus protected by the eyes on the street [24].

However, when referring to the virtual realm of dating apps, the user itself has the authority to decide whether to be seen by others in a public display or not. The diffuse 
boundaries which separate public and private is at the mercy of several factors [19]. Saiz García [21] describes how dating apps have contributed to the deconstruction of the borderline between what is public and private in spatial terms. The virtual realm is both simultaneously. Saiz Garcia [21] classifies profile pictures in Grindr according to the representational spaces - where pictures are taken - and to the subject of them - how the user is portrayed. Nevertheless, he proved that the proportion of pictures showing the identity of the user may vary according to the case-study area. Bumgarner [25] deepens into the use of images in homosexual dating apps and how the intentional display of them relates to the will of being seen. This will is related to the feeling of acceptance not exclusively by the homosexual community but also by the society in general terms. Thus, the presence of facepics - photographs with the full face shown - could be an indicator of the feeling of acceptance by the users and the perception of tolerance in an area.

This paper attempts to find correspondence not only between residential and demographical issues and the presence of Wapo users as an indicator of Sarasa's [17] behavioral patterns, but also use photographs with an intentional display of the user's identity as an indicator of Bumgarner's [25] perception of acceptance and tolerance to define creative areas.

\section{METHODOLOGY}

Wapo is a location-based dating app designed for smartphones and targeted to male homosexual users. It was first released on February 13th 2015 by Wapo \& Wapa Limited and it was self-defined as "The gay dating app where you can \#beyourself [26]. The app is based on GPS technology to attach a location trace to every profile, from which people nearby can be seen. It offers the possibility of creating public profiles with pictures and personal information about physical features (height, weight, age, etc.), a personal description and links to other social networks. The app does not limit the distance according to which other profiles are seen, but the number of profiles shown in the feed. Thus, the higher density of users in an area, the closer they are.

This social network was selected for this study due to the users that often use it in the context of the study. Wapo is a popular app in Spain among locals, but not among tourists and visitors, which tend to utilize other apps for the same purposes (such as Grindr and Hornet) [27]. This fact allows us to extract data related to locals rather than visitors in our final results.

To calculate user density, we consider the amount of users in several query radiuses from a given point, being (1) the given points the geometrical centroid of every neighborhood in the city and (2) the radius the maximum distance from the geometrical center to the border of the neighborhood. Therefore, we are able to cover their entire geometries and to reduce overlaps and blank spaces. Thus, the amount of users per square meter is calculated unitarily in every neighborhood independently from the size of it.

Since the results retrieved from the queries are only showing active users at the time of the search, the queries are performed in all 73 neighborhoods simultaneously. We performed them in different times and days of the week to get an average value, according to Table 1.

For every one of the 73 neighborhoods, it was registered: (1) the number of active users at the time of the query and (2) the number of active users with a recognizable face picture. The same data processing was performed to both indicators.

It was observed that the time shift did not affect the distributional amount of users between neighborhoods.

In other words, the amount of users remained proportional between query points independently from the time of the search, with minimum variances. Thus, it was calculated 
Table 1: Time distribution of queries performed in all neighborhoods.

\begin{tabular}{llll}
\hline Monday & Wednesday & Saturday & Sunday \\
\hline $8 \mathrm{am}$ & $8 \mathrm{am}$ & $8 \mathrm{am}$ & $8 \mathrm{am}$ \\
$4 \mathrm{pm}$ & $4 \mathrm{pm}$ & $4 \mathrm{pm}$ & $4 \mathrm{pm}$ \\
$11 \mathrm{pm}$ & $11 \mathrm{pm}$ & $11 \mathrm{pm}$ & $11 \mathrm{pm}$ \\
\hline
\end{tabular}

Table 2: Number of results obtained.

\begin{tabular}{lc}
\hline $\begin{array}{l}\text { Total number of } \\
\text { indicators registered } \\
\text { (neighborhoods * times }\end{array}$ & 1752 \\
$*$ indexes) & \\
\hline $\begin{array}{l}\text { Number of } \\
\text { neighborhoods }\end{array}$ & 73 \\
$\begin{array}{l}\text { Number of times each } \\
\text { query is performed }\end{array}$ & 12 \\
$\begin{array}{l}\text { Number of indicators } \\
\text { registered per query }\end{array}$ & 2 \\
$\begin{array}{l}\text { Total number queries } \\
\text { performed } \\
\text { (neighborhoods * times) }\end{array}$ & 876 \\
\hline
\end{tabular}

an average value for each neighborhood, reducing the data corpus from 876 query values (1752 indicators) to 73 average values (146 indicators) (see Table 2).

Since the interest of this work is not to study the neighborhoods separately but to define an overall view, final average values were normalized according to Jenks Natural Breaks formulae. Thus, the neighborhood with the lowest density receives the value 1 and the densest receives the value 10 . All the 71 values in between are grouped not equally graded but indexed [28].

Cross-referencing results from different sources and nature is needed to analyze all layers of information over the same physical space to drive conclusions. The data sources utilized in this paper are described as it follows (see Table 3).

\section{RESULTS}

The results observed from the computation of correspondence analysis calculations describe how variables are strongly segregated into two groups of correspondence. The first group is characterized to be more 'static' and are those retrieved from the City of Barcelona open data portals. However, the second group of variables is defined to be more 'dynamic' since they are dependent on spatial movement of people. These variables are those retrieved from Wapo. The following correlation matrix explains the correspondence between census data, and presence of venues (static variables), and active users or active users with a recognizable profile image (dynamic variables) separately. Size and average family income of the neighborhoods find no mathematical correspondence with any other variable described.

The factorial analysis revealed two strongly recognizable and strongly segregated patterns regarding the values gathered. These patterns are strongly followed by all case-study neighborhoods except 10. Sant Antoni (-4.7) and 8. L'Antiga Esquerra de l'Eixample (-2.6), 
which act independently, and 2. El Gòtic and 4. Sant Pere, Santa Caterina i la Ribera (average -2), which conform a cluster themselves.

Table 3: Data sources. Being (N) public quantitative data from the City of Barcelona [29]; (G) public GIS data from the City of Barcelona [29]; (W) data retrieved from Wapo queries; (S) self elaborated from the previous sources. In this context, urban dispersion is taken as the definition given by Taylor [30], and Fillion [31] calculated by measuring average distances of buildings to each other.

\begin{tabular}{|c|c|c|}
\hline $\begin{array}{l}\text { Socio- } \\
\text { economic } \\
\text { data }\end{array}$ & Urban form & $\begin{array}{l}\text { Wapo } \\
\text { Indicators }\end{array}$ \\
\hline $\begin{array}{l}\text { Overall } \\
\text { population }(\mathrm{N}) \\
\text { Area }(\mathrm{N}) \\
\text { Density }(\mathrm{N}) \\
\text { Average family } \\
\text { income }(\mathrm{N})\end{array}$ & $\begin{array}{l}\text { Ground floor } \\
\text { use }(\mathrm{N}) \\
\text { Dispersion (G-S) } \\
\text { Distance to the } \\
\text { city center (G-S) } \\
\text { Base cartography } \\
\text { (G) }\end{array}$ & $\begin{array}{l}\text { Active users } \\
\text { (W-S) } \\
\text { Active users } \\
\text { with image } \\
\text { (W-S) }\end{array}$ \\
\hline
\end{tabular}
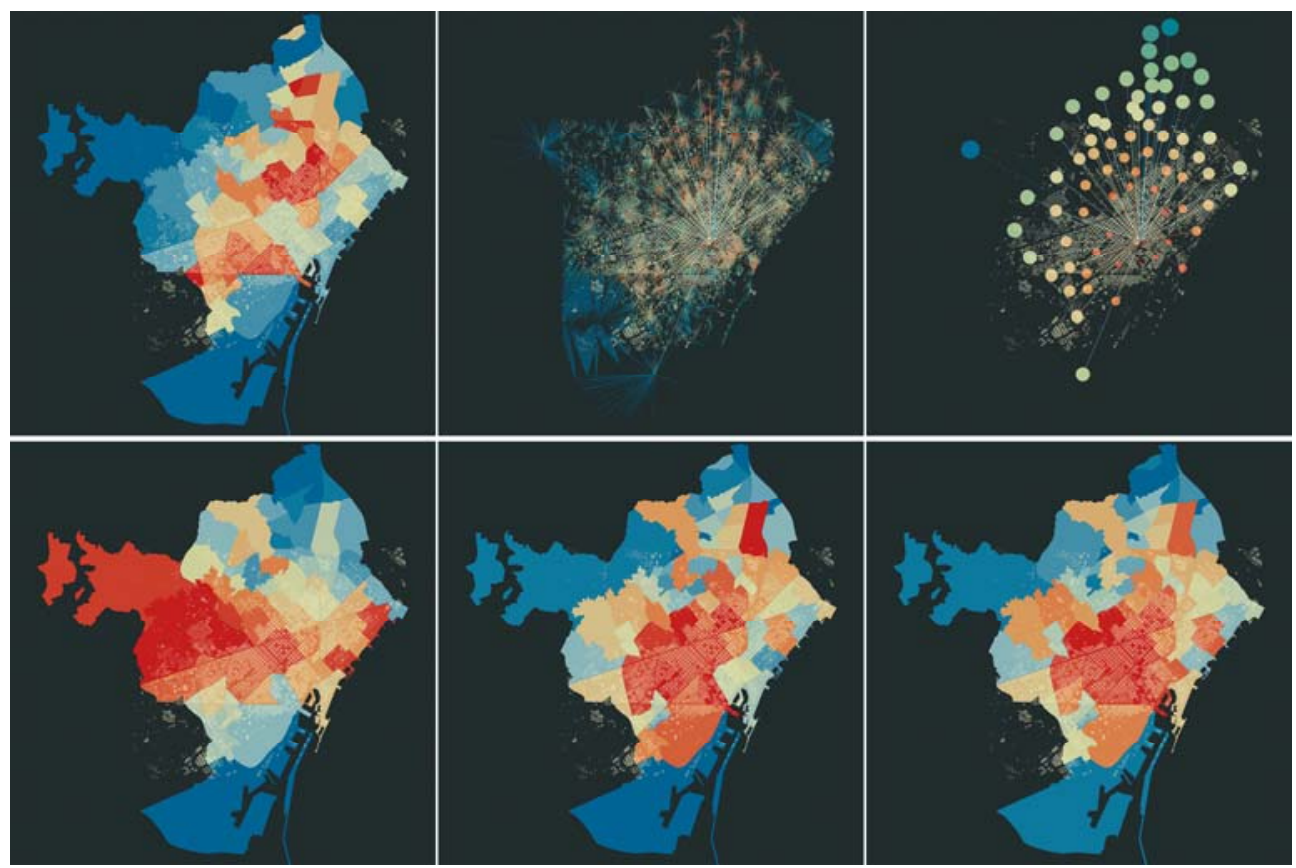

Figure 1: (Top left to bottom right) population density, dispersion, distance to the city center, average family income, overall population, number of venues in the ground floor. (Source:Self elaborated.) 
To address the lack of quantitative correspondence, all data layers described above were cross-referenced to find spatial correspondence with the results of the queries. These results were retrieved and represented as maps colored by Jenks Natural Breaks data subdivisions.

\subsection{Creative areas}

As seen in the correlation values per neighborhood, it is observed a separate tendency for Sant Antoni-L'Antiga Esquerra de l'Eixample and el Gòtic-Sant Pere. This two pairs of areas happen to share a common border and to be conformed by the same urban fabric (Barcelona grid and dense gothic fabric), so they can mentally be understood as a merge.

Sant Antoni-L'Antiga Esquerra de l'Eixample constitute the area popularly named as gayxample and it is characterized for the high presence of gay-friendly venues and business, with a similar open and tolerant character as Chueca area in Madrid [32]. The affinity to the gay scene defines the narrative and the identity of this area. Similarly, el Gòtic-Sant Pere, Santa Caterina i la Ribera has been witnessing a growing presence of the contemporaryhipster scene in the recent years, as a side effect of gentrification [33]. Regeneration of the area is being performed through creative businesses such as art galleries and hipster coffeehouses, characterized by the bohemian creative spirit of open-mindedness described by Florida [13].

Hence it is observed a correspondence between the mathematical discordance and the areas characterized by their affinity to the community, which is the target user of our main data source. Disproportionalities in the amount of active users of gay dating apps match those areas known as creative.

Table 4: Pearson's correlation matrix.

\begin{tabular}{lllllllll}
\hline & $\begin{array}{l}\text { Women } \\
\text { census }\end{array}$ & $\begin{array}{l}\text { Men } \\
\text { census }\end{array}$ & $\begin{array}{l}\text { Area } \\
\mathbf{m}^{2}\end{array}$ & $\begin{array}{l}\text { Profile } \\
\text { pictures }\end{array}$ & $\begin{array}{l}\text { Active } \\
\text { users }\end{array}$ & $\mathbf{\%}$ & Venues & Avg_income \\
\hline $\begin{array}{l}\text { Women } \\
\text { census }\end{array}$ & $\mathbf{1}$ & $\mathbf{0 , 9 8 8}$ & $-0,080$ & 0,344 & 0,384 & 0,247 & $\mathbf{0 , 8 4 7}$ & 0,229 \\
$\begin{array}{l}\text { Men } \\
\text { census }\end{array}$ & $\mathbf{0 , 9 8 8}$ & $\mathbf{1}$ & $-0,087$ & 0,365 & 0,398 & 0,261 & $\mathbf{0 , 8 4 2}$ & 0,189 \\
$\begin{array}{l}\text { Area m } \\
\mathbf{2}\end{array}$ & $-0,080$ & $-0,087$ & $\mathbf{1}$ & 0,120 & 0,083 & 0,144 & $-0,142$ & $-0,016$ \\
$\begin{array}{l}\text { Profile } \\
\text { pictures }\end{array}$ & 0,344 & 0,365 & 0,120 & $\mathbf{1}$ & $\mathbf{0 , 9 7 6}$ & 0,473 & 0,444 & $-0,044$ \\
$\begin{array}{l}\text { Active } \\
\text { users }\end{array}$ & 0,384 & 0,398 & 0,083 & $\mathbf{0 , 9 7 6}$ & $\mathbf{1}$ & 0,429 & 0,482 & $-0,016$ \\
\%R & 0,247 & 0,261 & 0,144 & 0,473 & 0,429 & $\mathbf{1}$ & 0,246 & $-0,242$ \\
$\begin{array}{l}\text { Venues } \\
\mathbf{0 , 8 4 7}\end{array}$ & $\mathbf{0 , 8 4 2}$ & $-0,142$ & 0,444 & 0,482 & 0,246 & $\mathbf{1}$ & 0,317 \\
$\begin{array}{l}\text { Avg_ } \\
\text { income }\end{array}$ & 0,229 & 0,189 & $-0,016$ & $-0,044$ & $-0,016$ & $-0,242$ & 0,317 & $\mathbf{1}$ \\
\hline
\end{tabular}



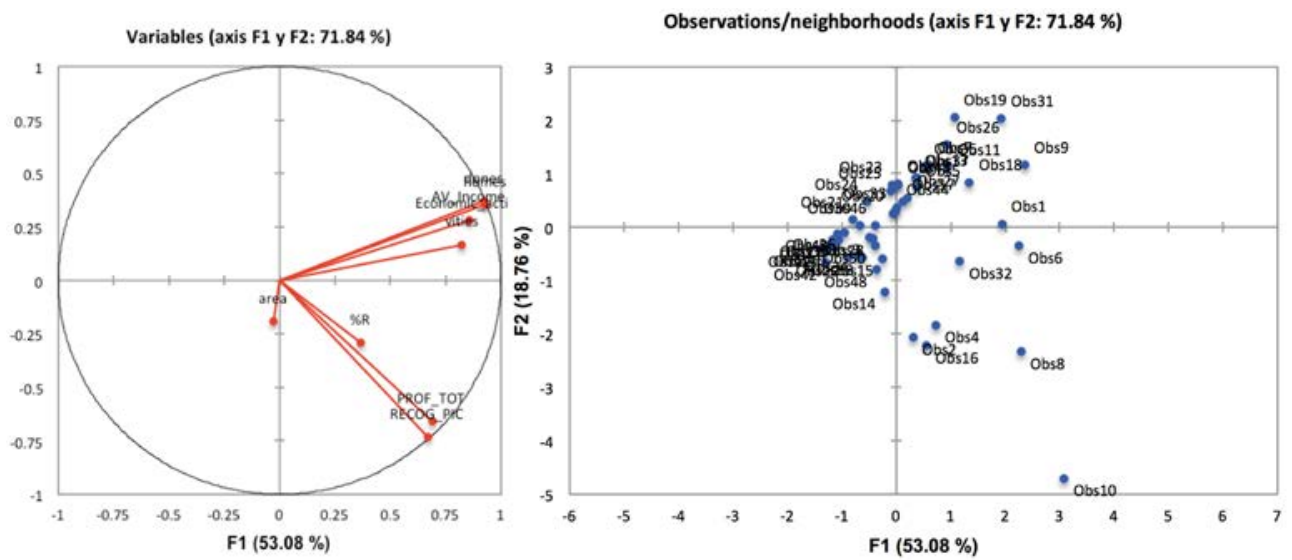

Figure 2: Correlation diagram with fractional loads (left) and correlation values per neighborhood (right). (Source: Self elaborated.)
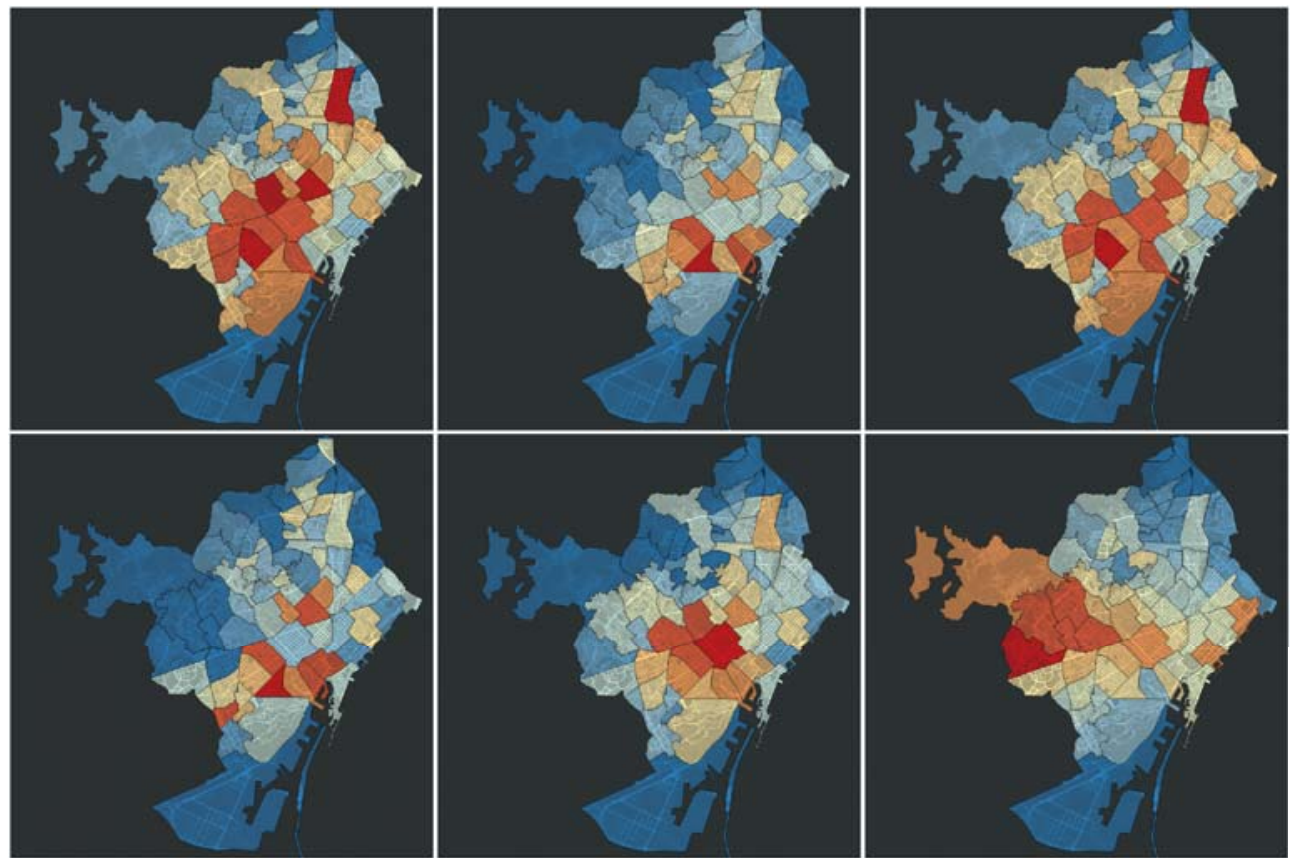

Figure 3: (Top left to bottom right) Women census, density of users, men census, recognizable profiles with pictures, venues/economic activities, average income. (Source: Self elaborated.) 


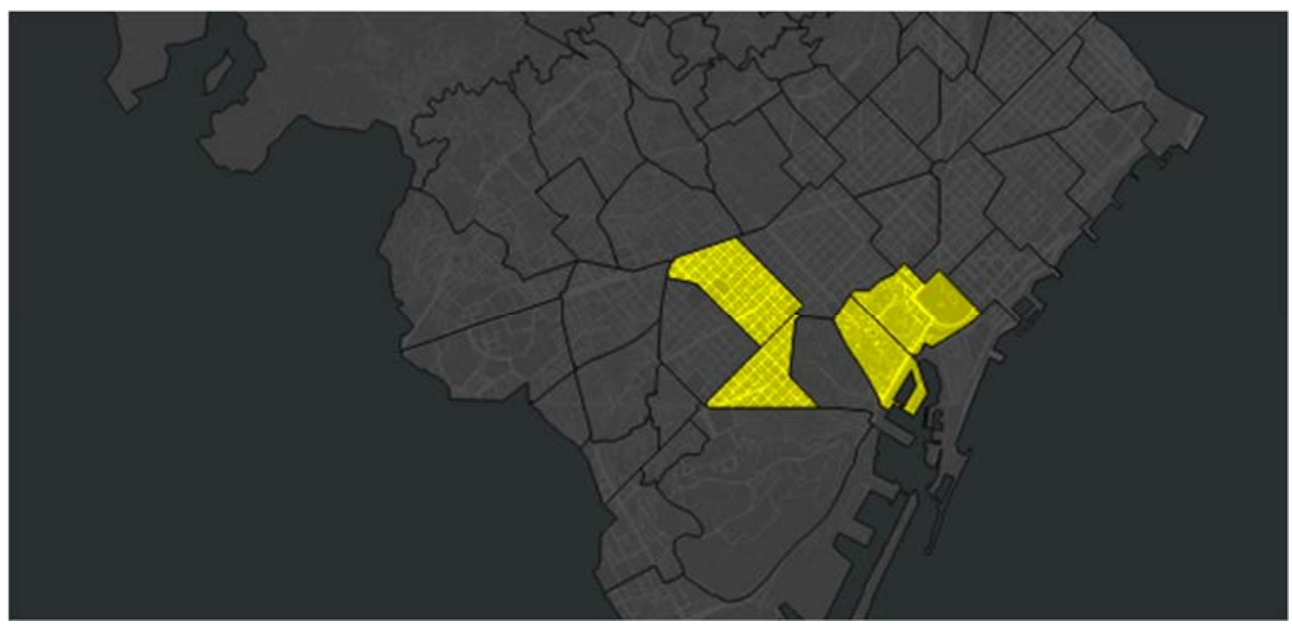

Figure 4: Neighborhood selected in yellow Sant Antoni-L'Antiga Esquerra de l'Eixample (west cluster) el Gòtic-Sant Pere, Santa Caterina i la Ribera (east cluster). (Source: Self elaborated.)

\section{DISCUSSION}

It is demonstrated that there is no mathematical correspondence between 'static' variables such as population or amount of venues registered by the census, and data activeness in a 'dynamic' dimension. This could be an indicator of the phenomena described by Cerrone (2015) as the detachment of the spatial features and social activeness, which is being produced with social networks taking a major role. City understood as a hybrid space (where physical space is merged with the virtual realm [34], [35]) allows people to move freely in the virtual space with no time, space or income boundaries. Socioeconomic inequalities noted in the income distribution and service inequalities found in the physical distribution of venues are not present in the virtual realm, since activity patterns are independent from both.

Thus observing the results, we can orientate a further discourse in four different directions:

1. The close matching (98\%) between male and female population point to a genderequal city the matching of both variables with amount of venues registered (84\%) point to equality in venues in the sense of services, commerce and possibility of activities performed in urban space. Results point to Barcelona as a socially equal city.

2. However, spatial distribution of income shows segregation between the central and west areas in comparison with the northern and southern neighborhoods, which show a slightly economic segregation. The lack of mathematical correspondence between average income data and the other values utilized in this paper limit the diagnosis for understanding the reason or the consequences of such.

3. Observing online activeness densities and their spatial distribution, we find that the places that do not follow statistical tendencies are those located in gay friendlycreative areas. Thus, these neighborhoods find a match between data and their own 
narratives and the shared local knowledge [32], [33], which is portrayed by outstanding levels of activeness in general terms (and in will of visibility and overall proportion of both amounts). In other words, not only there are more people being active in Wapo, but also the proportion between people showing intentionally an explicit profile image and people hiding themselves, is higher. Thus it could be understood that the shared local knowledge of the narrative of those areas makes them be defined as the "comfort zone" for the users, which concentrates the activeness in these creative neighborhoods.

4. Beyond the activeness levels, areas with an outstanding amount of profiles showed a higher proportion of profiles with an explicit recognizable picture. In other words, denser area had more face-pictures in proportion with the overall number of active users, than less dense areas. This phenomenon of people bringing people could be studied further as an indicator of areas of tolerance or affinity to a certain community. Not only these areas gather more people, but also the sense of community produced by this gathering contributes to the feeling of comfort and safety to show publicly a profile in a virtual place linked to a tolerant physical location. Thus, outstanding tolerant places could be detected by observing mathematical discordance in the proportion between active users and recognizable profiles.

\section{CONCLUSION}

By observing factorial correspondence in both offline and online data, particularities are detected. Areas which do not follow trends were identified are those whose narrative matches the specific user target of the app used as data provider in this paper. Going beyond the simplistic affirmation gay-friendly areas gather a higher amount of gay-targeted app users, it is found a spatial correspondence between both numbers and a mathematical independence from all other factors. This discordance was explained by the narrative of the places embraced by the local knowledge. Therefore, this paper showed a method to detect areas with a specific narrative that match affinities to a specific user online and offline profile, through the detection of quantitative discordances.

\section{REFERENCES}

[1] Grindr Press, "Grindr Fact Sheet. Grindr Press Kit," 2015, Online. www.grindr.com/press. Accessed on: 30 Jan. 2017.

[2] Brubaker, J.R., Ananny, M. \& Crawford, K., Departing glances: A sociotechnical account of 'leaving' Grindr. New Media Soc., 18(3), pp. 373-390, 2014.

[3] Carole, A., Licoppe, C., Rivière, C.A. \& Morel, J., Grindr casual hook-ups as interactional achievements. New Media Soc., 18(11), pp. 2540-2558, 2016.

[4] Rees, J.C., Andrés Jaque, sex apps and intimate strangers - a candid interview, 2016, Online. http://www.run-riot.com/articles/blogs/andrés-jaque-sex-apps-and-intimatestrangers-candid-interview. Accessed on: 03 Feb. 2017.

[5] Kitchin, R. \& Dodge, M., Code/space: Software and Everyday Life. MIT Press, 2011.

[6] Blackwell, C., Birnholtz, J. \& Abbott, C., Seeing and being seen: Co-situation and impression formation using Grindr, a location-aware gay dating app. New Media Soc., 17(7), pp. 1117-1136, 2015.

[7] Sharif, M., Gaydar Culture: Gay Men, Technology and Embodiment in the Digital Age, London: Routledge, 2016. 
[8] Easton, R., Will prudish app guidelines sink the iPhone? Xtra. Ca, 2009, Online. http://www.dailyxtra.com/canada/news-and-ideas/news/will-prudish-app-guidelinessink-the-iphone-52316. Accessed on: 30 Jan. 2017.

[9] Schwartz, R., Out of the grind? Grindr and teen queer identity work in rural US. Am. Anthropol. Assoc. Invit. Sess., 17, 2011.

[10] Schwartz, R. \& Halegoua, G.R., The spatial self: Location-based identity performance on social media. New Media Soc., 2014.

[11] Lazzarini, L. \& López Baeza, J., The mushrooms' street: The perception of urban transformations through Instagram. Urbanistica, 157, pp. 53-56, 2017.

[12] Arora, A., Florida, R., Gates, G.J. \& Kamlet, K., Human Capital, Quality of Place, and Location, Richard King Mellon Foundation: Pittsburgh, 2000.

[13] Florida, R., The rise of the creative class. Wash. Mon., 34(5), pp. 15-25, 2002.

[14] Clark, T.N., Urban amenities: lakes, opera, and juice bars: do they drive development? City as an Entertain. Mach., pp. 103-140, 2003.

[15] Glaeser, E.L., Review of Richard Florida's The Rise of the Creative Class, Harvard University: Cambridge, Massachusetts, 2004.

[16] Sassen, S., The Global City: New York, London, Tokyo, Princeton University Press, 2001.

[17] Sarasa, S., Porcel, S., Navarro, L. \& Thiers, J., Desindustrialización y crisis en la Barcelona postolímpica: ¿hacia una ciudad dual? Rev. EURE-Revista Estud. Urbano Reg., 44(131), 2015.

[18] Colomina, B., The split wall: Domestic vouyerism. Sex. Sp., 74, 1992.

[19] Colomina, B., Publicity and Privacy: Modern Architecture as Mass Media, MIT Press: Chicago, 1994.

[20] Jakob, M., The Technological Origins of Landscape, 2016.

[21] Saiz García, M., "Desmontando GRINDR. Usos, percepciones e implicaciones de la plataforma de contactos hombre-hombre," Universidad Politécnica de Madrid Universidad Complutense de Madrid, 2017.

[22] Whyte, W., Social Life of Small Public Spaces, New York, 1980.

[23] Gehl, J., Svarre, B., Press, I. \& Steenhard, K.A., How to Study Public Life, 2013.

[24] Jacobs, J., The Death and Life of Great American Cities, 1961.

[25] Bumgarner, B., Mobilizing the gay bar: Grindr and the layering of spatial context. Proceedings of Conference of the International Communication Association, 2013.

[26] Wapo, L., Wapa, Y., Limited, "Wapo," 2015, Online. wapoapp.com. Accessed on: 9 Jun. 2017.

[27] Gómez Beltrán, I., Resistencias estratégicas a la feminidad masculina en aplicaciones móviles (app) de contacto homosexual entre varones, 15, pp. 6-10, 2016.

[28] Jenks, G.F., The data model concept in statistical mapping. International Yearbook of Cartography, 7, pp. 186-190, 1967.

[29] Ajuntament de Bareclona, "Open Data BCN," Online. http://opendataajuntament.barcelona.cat/es. Accessed on: 20 Jul. 2002.

[30] Taylor, L., No boundaries: exurbia and the study of contemporary urban dispersion. GeoJournal, 76(4), pp. 323-339, 2011.

[31] Fillion, P., Suburban mixed-use centres and urban dispersion: what difference do they make? Environ. Plan. A Econ. Sp., 33(1), pp. 141-160, 2001.

[32] Peixoto, J.M., Usos y apropiación queer del espacio urbano: El caso GayEixample en Barcelona y Chueca, pp. 1-10, 2010.

[33] Salinas, V.F., Visibilidad y escena gay masculina en la ciudad española. Doc. d'Analisi Geogr., 49, pp. 139-160, 2007. 
[34] Saker, M. \& Evans, L., Everyday life and locative play: an exploration of Foursquare and playful engagements with space and place. Media, Cult. Soc., 2016.

[35] Wong, C., Smartphone location-based services in the social, mobile, and surveillance practices of everyday life, London School of Economics and Political Science, 2013. 